\title{
Modern techniques and problems in the restoration of Marlow Suspension Bridge
}

\author{
H. J. WADSWORTH \& A. WATERHOUSE
}

\section{Mr E. Bateson}

It is more than $\mathbf{3 0}$ years since I was involved in an investigation of the Marlow Bridge and the preparation of a scheme for strengthening the bridge for normal local traffic. The Ministry of Transport at that time were not interested in strengthening the bridge up to the practicable limit but would have given favourable consideration to its replacement by a new bridge capable of carrying the normal heavy traffic of that day. The new bridge proposal did not find favour with the local authorities who considered that heavy traffic should by-pass Marlow by means of a new bridge at some other crossing. This is now apparently accepted as the correct solution and the old bridge has been given a new lease of life.

56. One feature of the old bridge, which was particularly impressed on my memory, was the completely fallacious design of the bearings at the turning points on the towers. As may be seen from Fig. 15, these consisted of a curved link passing

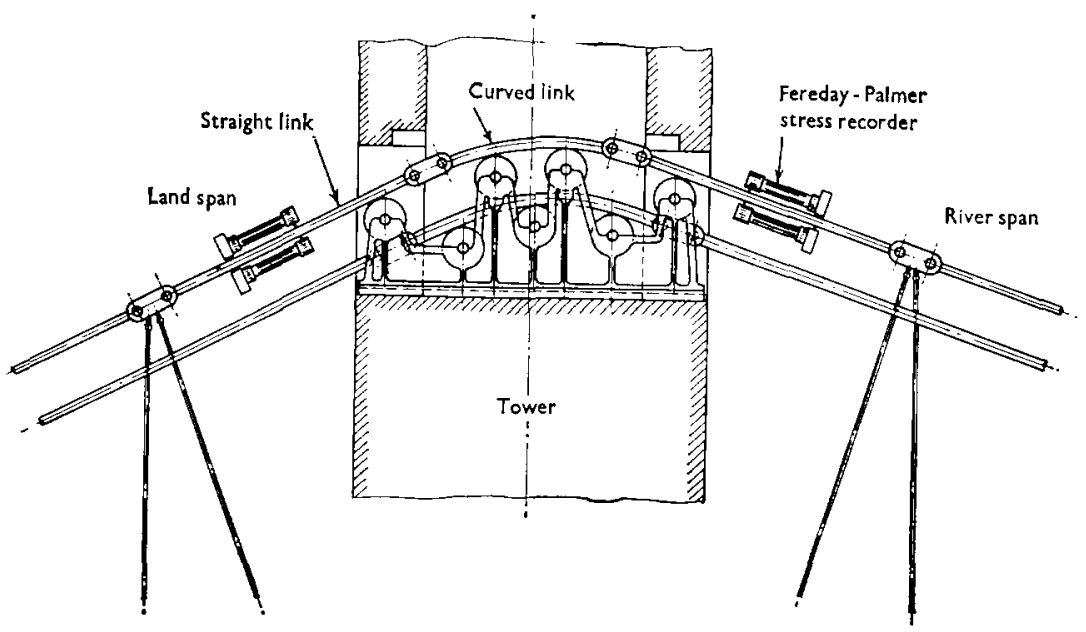

Fig. 15. Marlow Bridge chain bearing before reconstruction

over a number of rollers. A moment's consideration showed that these rollers were almost completely inoperative as the curved link could only move within the small range of elastic deformations. The adjoining straight link passed over a roller and although designed as a purely tension member was subjected to severe bending stresses at this point and the extreme fibre stresses recorded under the test loading ranged from

Paper published: Proc. Instn civ. Engrs, 1967, 37 (June) 297-316. 
2.2 tons/sq. in. tension to 1.9 tons/sq. in. compression. Additional bending stresses of indeterminate amount were no doubt similarly produced by the dead load of the bridge itself. The new bearings provide the requisite movement and at the same time enable the links to function exactly as intended.

57. Those responsible for the work are to be congratulated on preserving the beauty of the original structure and at the same time improving the usefulness of the bridge in that function which justifies its existence.

Mr B. G. R. Holloway, Rendel, Palmer \& Tritton

Having been associated with Marlow Bridge since 1930 I can now look back on the project with some detachment. I am left with the following impressions.

59. The imagination and skill which the designers and the constructors showed in completing the original bridge without the advantage of most of the design, fabrication and erection techniques described in this Paper are worthy of note.

60. Competitive tenders were called for and obtained and the work carried out with a relatively low value of claims at the end when the first assessment showed that the job could only be done on a cost plus basis. This, I think, was largely due to the fact that the formulated erection scheme which the tenderers were at liberty to accept, amend or substitute, was developed in considerable detail involving thirteen full size drawings including a sequence diagram and a timed critical path programme and considerable descriptive matter in the documents. From these it would appear that the tenderers had a clear idea of what was involved, both in activities and times and the details of the design which were controlled by the method of erection.

61. The supervisory staff at site were mainly young men who, though not inexperienced, had the advantage of not being hampered too much by tradition on a project with unusual features.

62. The almost complete disregard of weight and speed restrictions by somesections of the public rendered the restrictions nearly useless. On one occasion, with a two ton restriction and with only one old chain supporting the temporary deck, a brick lorry passed over the bridge. Why the deck did not collapse I do not know, the upper flanges of the old cross girders should have buckled as struts with even a 5 ton load. Bridges often derive considerable strength from road surfacing, balustrades, rigid joints, etc. but in the above instance, the only assistance afforded was the distribution effect of the temporary roadway which, under the resulting deflexion of about 6 in. must have been considerable. It was only the physical restriction of the 'goal posts' which eventually ensured compliance by road users.

\section{Mr S. Mercer}

I read with interest $(\$ 7)$ that the contract for the reconstruction of the Marlow Suspension Bridge 'was placed with Messrs Horseley Bridge and Thomas Piggott Ltd, Messrs Aubrey Watson Ltd being the sub-contractor for the civil engineering works'. If the reconstruction of the bridge is not civil engineering I would like to know what is.

Mr W. Walker, Site Agent, Horseley Bridge \& Thomas Piggott Ltd

I should like to congratulate both Authors on the excellent presentation of their Paper. Whilst the Paper is comprehensive there are further aspects of both the design and construction that $I$ feel may be of interest.

65. The welded lattice cantilevered extensions at the ends of the cross girders were utilized to carry the services across the main span of the bridge, the electricity and water on the upstream side and the GPO telephones on the downstream side. The installation of the services was achieved by making the lattice cantilever extensions at the ends of three cross girders adjacent to the Buckinghamshire tower loose, to enable up to $20 \mathrm{ft}$ lengths of service ducts to be inserted, the cantilever extensions being bolted to their respective cross girder once the ducts had been completed. A 
combination of these loose cantilever extensions and the fact that the footpaths were of timber construction enabled any future removal of the services for maintenance reasons to be carried out from deck level.

66. The level of the new deck was raised throughout to give an increase in level of approximately $23 \mathrm{in}$. at the centre of the main span. The reason for this increase in level of the deck was to achieve the same clearance below the bottom chord of the stiffening girder for river craft as was afforded by the old bridge at the underside of the timber deck, i.e. originally large river craft had to navigate between a pair of cross girders.

67. In addition to setting the chains in their unloaded state $3 \frac{1}{2} \mathrm{in}$. high at the centre of the main span, to allow for settlement as the dead load was introduced, the level was also corrected for the prevailing temperature above or below the design temperature of $68^{\circ} \mathrm{F}$.

68. The temporary timber roadway was restrained against transverse wind forces by wire guys fixed to the quarter points on the main span, each guy being anchored to a pair of Larssen piles which had been driven into the river bed. These piles were also utilized to moor the barges and to enable the barges to be manoeuvred and held in position during the erection of the deck.

69. The sequence of erection of the steel deck plates was modified at site to try to improve upon the initial time allowed for their erection and the transfer over of the temporary timber roadway supporting trestles. The scheme consisted of a gradual change over of the temporary timber roadway supporting trestles to the newly erected deck plates, the deck plates being erected in a logical order within a specific section of the bridge, to achieve as near as possible the introduction of uniform loading on the new chains. The time taken to erect the whole of the steel deck plates under the new scheme including the transfer over of the temporary timber roadway trestles was $4 \frac{1}{2}$ weeks compared with 6 weeks allowed by the critical path analysis under the original scheme.

70. An interesting problem was to devise a scheme to release the remaining axial load from out of the existing chains when they were hanging freely. The release of the axial load was achieved by fitting an arrangement of straining rods and beams at the centre of the main span so as to form a 'by-pass' for the two middle sets of chain links. The straining rods were loaded using a pair of hollow-centre 35 ton Simplex jacks; sufficient load being applied to release the whole of the load from the two middle sets of chain links. The two middle sets of chain links were then removed by cutting them up into sections. The load in the straining jacks was then gradually released by allowing the jacks to return slowly to their unloaded position, the chain settling down upon a series of cradles made from wire ropes (or the safety clamps in the case of the upper chain) attached at each knuckle position on the new upper chain. The remainder of the chain was then removed by cutting up into sections, working simultaneously from the middle of the main span and the anchor block ends towards the towers in order to achieve uniform loading on the new upper chain.

71. Finally I should like to express my thanks to all sub-contractors for the co-operation they gave throughout the whole of the contract.

\section{The Authors}

We agree with Mr Bateson's remarks that the design of the chain bearings of the old bridge was fallacious. The designer had however obviously anticipated some bending stresses when he had made the chain links over the bearings deeper than those elsewhere. A further bad point in the design was the use of rollers in journal bearings which involved axle friction rather than rolling friction. A recent inspection of the new bearings has shown that the rollers encased in the pitch-polyurethane are still functioning satisfactorily.

73. We would like to endorse wholeheartedly Mr Holloway's observations concerning the imagination and skill of the engineers who originally built this bridge in 
1830. Such men as these performed great feats of engineering with few, if any, of the facilities available today. We should indeed pay homage to them and it is to be hoped that their shades still walk with us and approve the skills of our time.

74. Mr Holloway was certainly correct in thinking that the detailed erection scheme prepared by the Consulting Engineers gave a very clear picture of the work involved and this was of great assistance to the Contractor at the tender stage. Despite this, however, the site work proved to be more costly than was originally envisaged. This was due to several causes:

(a) the difficulty in estimating the labour content of the rather unusual step-bystep sequenced erection programme since preparatory and completion work in programmed events tended to overlap adjacent events;

(b) the fact that this was a fixed-rate contract and that there was a much sharper increase in the costs of labour and consumables during the contract period than had been anticipated;

(c) the fact that, in common with most contracts of this type, payment for variations and additional work was fixed with reference to the original billed rates or other proportionate evaluation which did not necessarily represent the true cost of the work entailed.

This latter point has been mentioned in the Report on the implementation of the Banwell Report. ${ }^{4}$

75. With regard to Mr Holloway's third observation, we feel that it is essential to give competent young engineers as much responsibility as possible at an early stage in their careers so that they can prove their mettle and reap satisfaction from their work. This has certainly occurred on this contract and all concerned did a very good job.

76. Mr Holloway's final comment highlights a problem facing highway authorities generally with regard to the enforcement of weight restrictions on bridges. As a permanent arrangement, the only effective deterrent is a full-time patrol by a uniformed officer of the law and the cost of this would be prohibitive. There would appear to be a case for research into the possibility of linking an automatic detection device such as an electronic weighbridge with a visible and audible warning system and possibly a recording camera so as to effect a closer enforcement of the law.

77. With regard to Mr Mercer's comment, it is customary for constructional steelwork firms to refer, perhaps somewhat loosely, to foundations, abutments and concrete work as the civil engineering part of bridgework when, in fact, the whole of the work comprises this, as $\mathrm{Mr}$ Mercer quite rightly points out.

78. We are grateful to Mr Walker for providing further useful details of the construction procedure which it was not possible to include in the Paper.

79. In conclusion, we would like to bring up to date the cost figures given in the Appendix. The total cost of the work as determined by the final measurement was $£ 223000$ and not $£ 219000$, the difference comprising additions of approximately $£ 2000$ each to the superstructure steelwork and services respectively.

\section{Reference}

4. The report on the implementation of the Banwell Report by the working party o, the Economic Development Committee for building. 1967, HMSO 70/955 (July). 